\title{
Mutterschutz
}

\section{Mehr Freiheit für schwangere Ärztinnen}

\author{
Der Mutterschutz soll reformiert werden. Für angestellte schwangere \\ Ärztinnen bedeutet die Novelle mehr Freiheit: So sollen Arbeitsverbote \\ und der Ausschluss von Sonntagsarbeit Vergangenheit sein - sofern \\ die werdende Mutter das will.
}

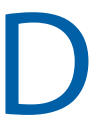
ie Regierung schickt sich an, den Mutterschutz $\mathrm{zu}$ reformieren und bringt damit auch Änderungen für Praxischefs als Arbeitgeber sowie Ärztinnen als Angestellte. Selbst Studentinnen und Schülerinnen sollen künftig Mutterschutz in Anspruch nehmen können. Die Neuregelung gehört zu einer umfassenden Reform des Mutterschutzgesetzes, mit der Familienministerin Manuela Schwesig (SPD) die fast 65 Jahre alten Regelungen entstauben möchte. Das Bundeskabinett billigte bereits ihren Gesetzentwurf. Künftig soll es demnach keine Arbeitsverbote mehr gegen den Willen der Schwangeren geben, was in der Vergangenheit vielen Ärztinnen Steine in den Weg gelegt hat. Denn weil Arbeitgeber haftungsrecht-liche Konsequenzen fürchten, werden Schwangere bisher zum Beispiel häufig aus dem OP verbannt, sobald sie öffentlich machen, dass sie ein Kind erwarten - was besonders für Ärztinnen in Weiterbildung schwerwiegende Folgen haben kann.

\section{Die Betriebsärztin im Feindbild}

„Unsere größten Feinde in Sachen Karriere sind aktuell nicht unser Partner oder Kinder, sondern die Betriebsärztinnen“, so Prof. Marion Haubitz, Chefärztin am Klinikum Fulda, auf einer Diskussionsveranstaltung zur weiblichen Karriere in der Medizin, zu der die Landesärztekammer Hessen im Mai eingeladen hatte. Viele Kolleginnen verschwiegen eine Schwangerschaft so lange wie möglich, um weiter im OP stehen zu können. „Wir tun, als ob schwangere Frauen krank wären. Damit legen wir uns selber Steine in den Weg“, kritisierte Haubitz die bisherige Regelung. Sie selbst habe gerade mit drei schwangeren Assistenzärztinnen zusammengearbeitet, berichtete sie. „Da haben wir die Arbeitszeitmodelle aufs Äußerste ausgereizt, und es ging." Um Frauen im Beruf - und vor allem in Kliniken - zu halten, seien solche flexibleren Arbeitszeitmodelle unverzichtbar. Die Reform des Mutterschutzgesetzes, das seit seines Inkrafttretens 1952 nur noch minimal verändert wurde, könnte dazu ein erster Schritt sein. Denn auch die Möglichkeit der Sonntagsarbeit wird erweitert, wenn die Betroffene das möchte. Die Schutzfrist, in der grundsätzlich nicht gearbeitet werden darf, beginnt unverändert sechs Wochen vor der Entbindung und endet in der Regel acht Wochen danach. Für Mütter behinderter Kinder soll diese Frist von acht auf zwölf Wochen erweitert werden. Der Bundestag muss der Reform allerdings noch zustimmen.

In der Novelle ist nun ebenfalls geändert, dass künftig auch schwangere Studentinnen in Mutterschutz gehen können. Nach Angaben des Familienministeriums gibt es in Deutschland jedes Jahr rund 20.000 schwangere Studentinnen und Schülerinnen.

\section{Lösung für Selbstständige kommt}

Das Vorhaben, den Mutterschutz auf Studentinnen zu erweitern, war bei Bundesbildungsministerin Johanna Wanka (CDU) zunächst auf großen Widerstand gestoßen. Deshalb lagen die Gesetzespläne monatelang auf Eis. Letztlich verständigte sich die große Koalition aber darauf, dass Ausnahmen von den strengen Mutterschutzregelungen möglich sein sollen - etwa wenn eine schwangere Studentin kurz vor der Entbindung freiwillig eine wichtige Klausur schreiben möchte.

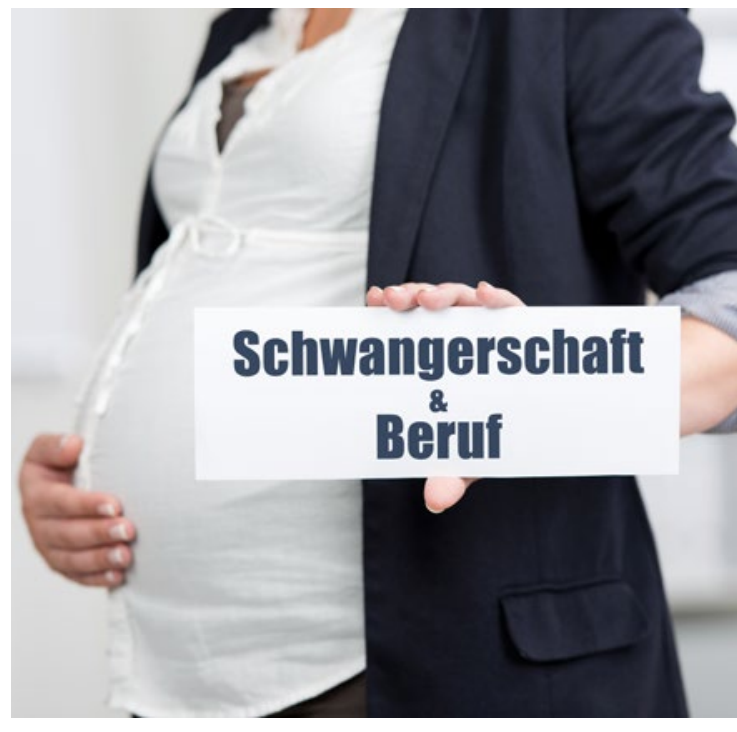

Der Deutsche Gewerkschaftsbund (DGB) hält das Reformpaket für nicht ausreichend. Die stellvertretende DGBVorsitzende Elke Hannack bemängelte, Beamtinnen, Richterinnen und Soldatinnen würden nicht in das bundesgesetzliche Mutterschutzrecht einbezogen. „Das ermöglicht ohne Not Abweichungen vom einheitlichen Schutzstatus." Das Familienministerium wies diesen Vorwurf als unberechtigt zurück. Der Mutterschutz für die genannten Berufsgruppen werde zwar aus gesetzestechnischen Gründen in gesonderten Rechtsverordnungen geregelt, doch bei der Umsetzung sei der gleiche Schutz gewährleistet wie für alle schwangeren und stillenden Frauen. Die Gewerkschaft Verdi forderte außerdem, neben Angestellten müssten alle erwerbstätigen Frauen in das Mutterschutzgesetz einbezogen werden, nicht nur - wie jetzt vorgesehen - die arbeitnehmerähnlich Selbstständigen.

Ministerin Schwesig versicherte derweil, sie wolle in den kommenden Jahren auch eine Lösung für selbstständige Frauen finden. Dieses Vorhaben werfe allerdings neue Fragen auf. Jana Kötter 